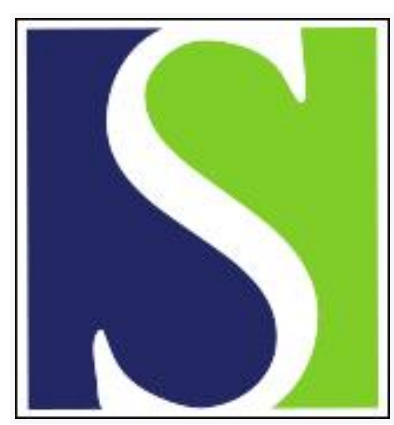

Scand J Work Environ Health 2004;30(5):356-361

https://doi.org/10.5271/sjweh.823

Issue date: Oct 2004

Ovarian cancer and occupational exposure among pulp and paper employees in Norway

by Langseth $\mathrm{H}$, Kjærheim $\mathrm{K}$

Affiliation: Cancer Registry of Norway, Institute of Population-based Cancer Research, Montebello, N-0310 Oslo, Norway. hilde.langseth@kreftregisteret.no

Refers to the following texts of the Journal: 1999;25 suppl 2:1-116 1996;22(1):14-26 2000;26(2):99-105 1998;24(3):175-182

Key terms: asbestos; cancer of the ovary; dust; female; nested case-control study; Norway; occupational exposure; ovarian cancer; pulp and paper employee; talc; worker

This article in PubMed: www.ncbi.nlm.nih.gov/pubmed/15529799 


\title{
Ovarian cancer and occupational exposure among pulp and paper employees in Norway
}

\author{
by Hilde Langseth, MSc, ${ }^{1}$ Kristina Kjærheim, $P h D^{1}$
}

\begin{abstract}
Langseth $\mathrm{H}$, Kjærheim K. Ovarian cancer and occupational exposure among pulp and paper employees in Norway. Scand J work Environ Health 2004;30(5):356-361.
\end{abstract}

\begin{abstract}
Objectives A cohort study of female pulp and paper workers in Norway has shown a significantly increased risk of ovarian cancer. Other than the involvement of hormonal and reproductive factors, little is known of the etiology of ovarian cancer. Asbestos and talc are two agents hypothesized to influence the development of the disease. The present study aimed to investigate the association between ovarian cancer and occupational exposure to asbestos, talc, and total dust among Norwegian pulp and paper workers.

Methods Forty-six cases of ovarian cancer, with four controls each, were included in the study. Occupational exposure was assessed by combining work histories from personnel files, questionnaire information about production processes, and exposure assessments from the mills. To obtain information about possible confounders, cases and controls were invited to participate in a personal interview.

Results The odds ratio for asbestos exposure was 2.02, 95\% confidence interval 0.72-5.66. For talc exposure, the odds ratio was 1.10, and for ever exposure to total dust, it was below 1.00. The risk estimates did not essentially differ after adjustment for possible confounding variables.

Conclusions The results do not confirm an association between exposure to asbestos, talc, and total dust and ovarian cancer among Norwegian pulp and paper workers. However, the odds ratio for asbestos exposure was doubled, and control for established nonoccupational risk factors did not change the estimate. Therefore, the possibility that exposure to substances in the work environment contributes to the elevated risk cannot be rejected.
\end{abstract}

Key terms asbestos, cancer of the ovary, dust, female workers, nested case-control study, talc.

Ovarian cancer is one of the most common gynecological neoplasms among women today, especially in industrialized countries. Ovarian cancer is a hormone-related disease, and estrogens are known to have an adverse effect. This effect is supported by several studies showing that the inhibition of ovulation through child-bearing, oral contraceptive use, and breast-feeding reduces the risk (1). Inherited mutations in the breast cancer genes $B R C A-1$ and $B R C A$ 2 account for approximately $5 \%$ of all cases (2).

Results from a study of 4247 Norwegian female pulp and paper workers showed a significantly increased risk of ovarian cancer (observed 37 cases, expected 24 cases, standard incidence ratio 1.5, 95\% confidence interval 1.07-2.09), mainly among women working in the paper departments (3). The risk was highest in the younger age groups, whereas in the general Norwegian population the occurrence is highest among women aged 65 years or older (4).

Over the last decade, there has been a growing interest in the hypothesis that occupational and environmental exposures may contribute to the development of ovarian cancer. Occupational groups of women who have been investigated and found at significant risk are, among others, women compensated for asbestosis in Italy (5), bookbinders in Russia (6), textile workers in the Nordic countries (7), and chicken farmers in Norway (8).

The role of asbestos in the causation of cancers other than those of the lung, pleura, and peritoneum is uncertain. Asbestos fibers are hypothesized to induce inflammation in the epithelium of the ovaries and further act as an initiator or promoter in the carcinogenesis of ovarian cancer (9). Asbestos fibers have been identified in tissue blocks from ovaries among women with both cancer and other diseases of the ovaries (10).

As early as 1960, it was found that women with pulmonary asbestosis tended to have ovarian and peritoneal neoplasms more often than other women (11). Increased mortality of ovarian cancer, as well as cancer of the lung and pleura, has been shown for asbestos-exposed gas-mask workers in two factories in

1 Cancer Registry of Norway, Institute of Population-based Cancer Research, Oslo, Norway.

Reprint requests to: Ms Hilde Langseth, Cancer Registry of Norway, Institute of Population-based Cancer Research, Montebello, N-0310 Oslo, Norway. [E-mail: hilde.langseth@ kreftregisteret.no] 
England (12), female gas-mask assemblers (13), and asbestos textile workers (14).

Talc is an agent with mineralogical similarities to asbestos, and it is often contaminated with asbestos (15). Results from several investigations have indicated that genital exposure to talc through its use on sanitary napkins or underwear, or by direct perineal application, increases the risk of ovarian cancer (16, 17). Furthermore, the risk seems to decrease among women who have undergone prior tubal ligation or hysterectomy (1). However, a recent meta-analysis concluded that no causal relation has been confirmed, and dose-response relationships have not been shown (18). Talc has been identified in tissue blocks from ovaries (19).

In the pulp and paper industry, relatively large quantities of asbestos have been used as an insulation material in boilers and in the breaks of slitterwinders and other rolling machines. Norwegian male pulp and paper workers had a significantly increased risk of pleural mesothelioma (20). This observation indicates that asbestos has been a considerable air pollutant in this industry. Talc has also been widely used as a coating agent-added in the paper mills.

Dust, especially paper dust, has been a main contaminant in the work atmosphere of female workers, and the dust may be a carrier of other air pollutants. Measurements of airborne dust in a Swedish soft paper mill showed that the dust also contained fibers other than cellulose (21).

A recent review of epidemiologic studies on occupational and environmental risk factors related to ovarian cancer concluded that current knowledge in this field is limited (22). We therefore found it worthwhile to investigate our observation among occupationally exposed women further. The aim of the study was to test the hypothesis that the increased risk of ovarian cancer among Norwegian pulp and paper workers was associated with exposure to asbestos, talc, and total dust.

\section{Study population and methods}

Cases and controls were selected from the total cohort of 4247 female pulp and paper workers from 10 different mills. The cohort has been previously described in detail (3).

\section{Selection of the cases and controls}

The case group consisted of 46 persons with epithelial ovarian cancer, registered with the Cancer Registry of Norway and generated by the pulp and paper cohort during a follow-up period from 1953 to 1999. One person with a germ-cell tumor was excluded from the material. An experienced oncologist reviewed all the histological records in the Cancer Registry for each case and an equal number of persons for the control group with ovarian cancer outside the pulp and paper industry. Eleven of the cases were tumors of borderline malignancy, mostly stage I, and 35 were invasive tumors, mostly stage III.

Four persons were drawn as controls for each case by incidence density sampling (ie, they had to be a member of the cohort at the time of diagnosis of the case). Each control was individually matched to a case by birth year \pm 2 years. The controls had to be free of ovarian cancer and hold intact ovaries. Since the cohort consisted of many elderly persons, we expected a possible loss of available controls. We therefore selected two extra controls to be used if a person was dead or had emigrated and no relatives could be traced, if a person had a type of disease that made her unable to carry out an interview, or more than two controls for one case refused to participate. Five controls were excluded from the analyses because their ovaries were removed before the date of diagnosis of the case. The overall analyses included all 46 cases and 179 controls with complete work histories from the historical files. A description of the material used in the study is given in table 1 .

\section{Exposure assessments}

Work history was obtained from the personnel files of each mill. Departments, job titles, and date of start and end of employment in specific work activities were registered for all the cases and controls. A questionnaire, including information about production processes, use of specific agents, and changes over the years, was filled out by industrial hygienists and

Table 1. Number of persons included as cases and controls in the overall analyses and the subanalyses according to the descriptive data.

\begin{tabular}{lcr}
\hline Descriptive data & $\begin{array}{c}\text { Cases } \\
(\mathrm{N})\end{array}$ & $\begin{array}{c}\text { Controls } \\
\text { (N) }\end{array}$ \\
\hline Observed & 46 & 184 \\
Excluded ${ }^{\mathrm{a}}$ & - & 5 \\
Included in overall analyses & 46 & 179 \\
Nonrespondents & 11 & 77 \\
Extra persons invited & - & 33 \\
$\quad$ Interviewed & - & 19 \\
Included in the subanalyses & 35 & 121 \\
Interview persons & & \\
$\quad$ Self-respondents & 10 & 90 \\
$\quad$ Next of kin & & \\
$\quad$ Spouse & 3 & 6 \\
$\quad$ Child, sibling & 16 & 20 \\
$\quad$ Other & 6 & 5 \\
\hline
\end{tabular}

a Excluded because their ovaries were removed before the cases diagnosis.

Scand J Work Environ Health 2004, vol 30, no 5 
senior employees at each mill. Exposure assessments for the Norwegian mills were extracted from PAPDEM (pulp and paper department exposure matrix), an international database including measurements of 25 major agents in the pulp and paper industry in 15 countries (23). The assessment is specific to mill, work department, agent, and time period. Most of the measurements were from 1980 or later, and they were only used as exposure indicators.

Based on the questionnaire and PAPDEM information, table 2 shows the groups that were considered to have been exposed to asbestos, talc, and total dust in the pulp and paper industry and in work outside the industry. Separate analyses were carried out for the following five departments: (i) sulfite, sulfate and stock preparation departments (merged because of a small number of women in these departments), (ii) rayon plant (only one of the 10 mills included had rayon production), (iii) paper department, (iv) maintenance and laboratory department, and (v) clerical department. Duration of employment $(<3,3-$ 5 , and $>5$ years), time since first exposure to diagnosis of the case $(<15,15-30$, and $\geq 30$ years $)$ and year of first exposure (before 1950, between 1950 and 1960 , and after 1960) were used as indicators of occupational exposure.

\section{Interview data}

To collect information about possible confounders, all the persons in the case and control groups were invited to participate in a personal interview. The interview preferably took place in an office at the mills or, alternatively, in a private residence or institution or by telephone. Three specially trained professional female interviewers carried out the interviews. An informed consent form was signed before the interview started.

The interview included questions on complete occupational history, possible household asbestos exposure defined as having a husband or other members of the household ever employed as a plumber, stoker, insulation worker, machine worker on a boat, or other asbestos-related occupations. We also asked

Table 2. Job categories considered to result in exposure to asbestos, talc, or total dust.

\begin{tabular}{lll}
\hline Agent & $\begin{array}{l}\text { Exposed in the pulp } \\
\text { and paper industry }\end{array}$ & Exposed elsewhere \\
\hline Asbestos & $\begin{array}{l}\text { Maintenance workers, laboratory } \\
\text { workers, chlorine plant workers }\end{array}$ & Electrical industry workers \\
Talc & $\begin{array}{l}\text { Paper mill workers, sulfite mill } \\
\text { workers, maintenance workers, } \\
\text { stock preparation workers }\end{array}$ & $\begin{array}{l}\text { Cosmetic industry workers } \\
\text { rubber industry workers }\end{array}$ \\
Total dust & $\begin{array}{l}\text { Paper mill workers, sulfite mill } \\
\text { workers, stock preparation } \\
\text { workers, storage workers }\end{array}$ & $\begin{array}{l}\text { Paper workers in mills other } \\
\text { than those included in the } \\
\text { pulp and paper cohort }\end{array}$ \\
\hline
\end{tabular}

whether potential asbestos-exposed persons brought their workclothes home after work or not. Information about talc use on sanitary napkins, underwear, or diapers was obtained. Fertility pattern was registered as number of children, age at birth of first and last child, age at menarche and menopause, and oral contraceptive use. Hereditary variables were obtained by asking about ovarian and breast cancer among first- and second-degree relatives. Questions were asked about sterilization, hysterectomy, and operations in the abdominal cavity. Finally, information about smoking habits, height, and weight was obtained.

Eighty-eight persons initially refused to participate in the interviews because of old age or for medical or other reasons. Thirty-three controls from the additionally selected group were invited, and 19 were interviewed, giving a response rate of $76.1 \%$ for the cases and $65.7 \%$ for the controls. The analyses, including control for possible confounding variables, were based on 35 cases and 121 controls (table 1).

\section{Statistical analyses}

Odds ratios (ORs) and their $95 \%$ confidence intervals ( $95 \%$ CI) were derived from conditional logistic regression models using the statistical program package STATA (24).

The results have been presented according to two steps of analysis: first, for the full set of cases and controls, according to ever-never exposure to asbestos, talc and total dust based on occupational histories and, second, for the set of cases and controls who were interviewed, with adjustment for possible confounders, in addition to analyses of secondary asbestos exposure and hygienic talc use.

\section{Results}

Due to the small number of cases, all the histological types were merged in the analyses. Odds ratios were estimated for three exposure agents, asbestos, talc and total dust. A nonsignificant increased risk was found for ever asbestos exposure, with an odds ratio of 2.02. For talc exposure, the odds ratio was 1.10 , and for ever exposure to total dust the odds ratio was 0.77 (table 3 ).

Six cases and twelve controls were considered to be exposed to asbestos. They were working as cleaners in the maintenance department, electricians, painters, chlorine plant workers, or viscose workers. Regarding asbestos exposure, the analyses of duration of work, time since first employment to cancer diagnosis, and time of first employment showed no clear trend in the risk estimates. For talc exposure, the risk was 
Table 3. Odds ratios and 95\% confidence intervals for the women exposed to asbestos, talc, and total dust in the Norwegian pulp and paper industry, for the full set of cases and controls.

\begin{tabular}{|c|c|c|c|c|}
\hline \multirow[t]{2}{*}{ Exposure } & \multicolumn{2}{|c|}{$\begin{array}{c}\text { Number of } \\
\text { exposed persons }\end{array}$} & \multirow[t]{2}{*}{$\begin{array}{l}\text { Odds } \\
\text { ratio }\end{array}$} & \multirow{2}{*}{$\begin{array}{c}95 \% \\
\text { confidence } \\
\text { interval }\end{array}$} \\
\hline & Cases & Controls & & \\
\hline \multicolumn{5}{|l|}{ Asbestos } \\
\hline Never & 40 & 167 & 1.00 & .. \\
\hline Ever & 6 & 12 & 2.02 & $0.72-5.66$ \\
\hline \multicolumn{5}{|l|}{ Talc } \\
\hline Never & 23 & 93 & 1.00 & .. \\
\hline Ever & 23 & 86 & 1.10 & $0.56-2.18$ \\
\hline \multicolumn{5}{|l|}{ Total dust } \\
\hline Never & 12 & 38 & 1.00 & .. \\
\hline Ever & 34 & 141 & 0.77 & $0.35-1.68$ \\
\hline
\end{tabular}

highest for those with first employment before 1950 (not shown). The analyses did not show any trends in the odds ratios for the time variables for total dust exposure. The number of women exposed to any of the three exposure agents outside the pulp and paper industry were very low, and results are not presented.

The odds ratios for ever working in the paper departments and the maintenance and laboratory departments were 1.28 and 1.31 , respectively (table 4). No increased risk was associated with work in the production departments, the rayon plant, or the clerical departments.

\section{Interview data}

Among those participating in the interview, the odds ratio for ever asbestos exposure was 2.18 (95\% CI 0.53-9.05) (not shown). Adjustment for possible confounders such as number of children, breastfeeding, age at birth of first and last child, age at menarche and menopause, smoking habits, and family history of ovarian or breast cancer did not essentially change the risk estimates. The adjusted odds ratios for exposure to talc and dust were almost the same as the unadjusted ones (not shown). As a result of low statistical power, only one confounding variable was taken into the analyses at a time. Categories of unknown answers were excluded from the analyses.

\section{Household exposure and hygienic talc use}

Household exposure to asbestos through the husband or other family members living in the same house was reported for 16 cases and 70 controls. The conditional logistic regression analyses showed a lower risk among those exposed than among those not exposed (table 5). The risk was also lower for those whose family members brought their workclothes home after work. Use of talc on the genital area for personal hygiene gave an odds ratio of 1.15 (table 5).
Table 4. Odds ratios and 95\% confidence intervals for the employees in five departments of the Norwegian pulp and paper industry, for the full set of cases and controls.

\begin{tabular}{|c|c|c|c|c|}
\hline \multirow[t]{2}{*}{ Department } & \multicolumn{2}{|c|}{$\begin{array}{l}\text { Number of } \\
\text { workers }\end{array}$} & \multirow[t]{2}{*}{$\begin{array}{l}\text { Odds } \\
\text { ratio }\end{array}$} & \multirow{2}{*}{$\begin{array}{c}95 \% \\
\text { confidence } \\
\text { interval }\end{array}$} \\
\hline & Cases & Controls & & \\
\hline \multicolumn{5}{|c|}{ Sulfite, sulfate and stock preparation } \\
\hline Never & 43 & 168 & 1.00 & .. \\
\hline Ever & 3 & 11 & 1.05 & $0.26-4.17$ \\
\hline \multicolumn{5}{|l|}{ Rayon plant } \\
\hline Never & 42 & 156 & 1.00 & $0.22-1.98$ \\
\hline Ever & 4 & 23 & 0.66 & $\cdot \cdot$ \\
\hline \multicolumn{5}{|c|}{ Paper department } \\
\hline Never & 21 & 91 & 1.00 & .. \\
\hline Ever & 25 & 88 & 1.28 & $0.65-2.50$ \\
\hline \multicolumn{5}{|c|}{ Maintenance and laboratory workers } \\
\hline Never & 42 & 167 & 1.00 & .. \\
\hline Ever & 4 & 12 & 1.31 & $0.40-4.30$ \\
\hline \multicolumn{5}{|c|}{ Clerical workers } \\
\hline Never & 30 & 116 & 1.00 & .. \\
\hline Ever & 16 & 63 & 0.97 & $0.47-2.00$ \\
\hline
\end{tabular}

Table 5. Odds ratios and 95\% confidence intervals for household exposure to asbestos. Included in the table are also risk estimates for talc use for personal hygiene purposes. Only the set of cases and controls who participated in the interview are included.

\begin{tabular}{|c|c|c|c|c|}
\hline \multirow[t]{2}{*}{$\begin{array}{l}\text { Exposure } \\
\text { indicators }\end{array}$} & \multicolumn{2}{|c|}{$\begin{array}{c}\text { Number of } \\
\text { exposed persons }\end{array}$} & \multirow[t]{2}{*}{$\begin{array}{l}\text { Odds } \\
\text { ratio }\end{array}$} & \multirow{2}{*}{$\begin{array}{c}95 \% \\
\text { confidence } \\
\text { interval }\end{array}$} \\
\hline & Cases & Controls & & \\
\hline \multicolumn{5}{|l|}{ Asbestos } \\
\hline \multicolumn{5}{|c|}{ Household exposure ${ }^{a}$} \\
\hline Never & 13 & 45 & 1.00 & .. \\
\hline Ever & 16 & 70 & 0.82 & $0.35-1.91$ \\
\hline \multicolumn{5}{|c|}{ Work clothes brought home ${ }^{b}$} \\
\hline Never & 20 & 71 & 1.00 & .. \\
\hline Ever & 12 & 49 & 0.86 & $0.38-1.98$ \\
\hline \multicolumn{5}{|l|}{ Talc } \\
\hline \multicolumn{5}{|c|}{ Talcuse by personal hygiene } \\
\hline Never & 7 & 42 & 1.00 & .. \\
\hline Ever & 12 & 53 & 1.15 & $0.41-3.21$ \\
\hline
\end{tabular}

\section{Discussion}

Our study showed a nonsignificant odds ratio of 2.02 for asbestos exposure. The result remained stable after control for established nonoccupational risk factors. This finding indicates that asbestos exposure may be one contributing factor in the development of ovarian cancer among Norwegian pulp and paper workers. No associations were found between ovarian cancer and occupational exposure to talc or total dust.

The distinction between ovarian cancer and peritoneal mesotheliomas may be difficult to observe. To try to ensure that the included cases were correctly 
diagnosed, we used an experienced gynecological oncologist to review all the histopathological records in the Cancer Registry. However, we cannot be sure that none of the ovarian cancer cases were peritoneal mesotheliomas, but we believe the possibility is very low.

Only a small proportion of the female pulp and paper workers had been directly occupationally exposed to asbestos, and it is difficult to demonstrate a true association between exposure and outcome in this specific study. The sample size of our study was small, and the statistical power was therefore low. A priori calculations showed a $53 \%$ probability of achieving a significant result at the 5\% level if the odds ratio was 2.0. Our study was, however, based on a large cohort of female industrial workers, and we had complete job descriptions for all the workers, production data from the mills, and some exposure assessments. These data enabled us to estimate the risk related to specific work exposures. Earlier studies have focused on large occupational groups, being mainly based on census data, without specific exposure information.

Asbestos is known to cause cancer in wives and children of heavily exposed asbestos workers $(25,26)$. This association may indicate that even household exposures may play a role in the development of asbestos-related cancers. Furthermore, an association between environmental asbestos exposure and malignant mesothelioma of the pleura has been observed (27).

Results from British and Finnish studies have been contradictory with regard to the association between ovarian cancer and asbestos exposure. One explanation may be that different types of asbestos were used in the two countries, and these types of asbestos may have different effects on the target organ. One of the British studies found a significant association between crocidolite exposure and ovarian cancer, but no increased risk among chrysotile-exposed women (12). The Finnish study investigated women exposed to anthophyllite asbestos and found no increase in risk. This type of asbestos seems to have lower carcinogenic potential in mesothelial tissue than in lung tissue (28).

Women in pulp and paper mills have traditionally worked in the paper departments in the packing and sorting of paper or as clerical workers or cleaners, which are assumedly jobs without asbestos exposure. An international mortality study on asbestos exposure and pleural and lung cancer among pulp and paper industry workers emphasized that asbestos dust is not considered to be one of the main occupational exposures in this industry, although, on the other hand, it is not negligible. Of 24 pleural cancer cases, they considered 10 as never exposed and 14 as exposed to asbestos, and they expressed a concern that asbestos exposure may have been underestimated and misclassified (29). Such misclassification and underestimation may also be the case in our study.

Talc-exposed women did not have an increased risk of ovarian cancer. One possible explanation for this finding may be that most of the talc used in Norwegian pulp and paper mills is not fibrous (ie, does not contain asbestiform fibers such as tremolite or anthophylite). According to the data collected on the production processes at each mill, only one of the 11 mills used fibrous talc (unpublished observations).

Dust has been a common exposure in the paper departments that employed many of the women. In our study there was no significant association between total dust exposure and ovarian cancer. However, one Swedish study found a significantly increased risk of ovarian cancer among paper and packaging workers (30). Other studies have shown a nonsignificant increase in risk among paper workers $(31,32)$.

Among the interviewed persons, $71.4 \%$ of the patients and $28.6 \%$ of the controls were dead; therefore, much more information about the cases was collected from relatives than for the controls. This circumstance may have introduced problems with recall bias. Missing values with regard to household asbestos exposure may contribute to an underestimation of the association between household exposure and ovarian cancer. Experience from other studies has indicated that information obtained from relatives is generally valid, except for information on occupational exposure, which should be collected instead from colleagues or personnel departments (33).

The questions on hygienic talc use resulted in many missing values among the proxy respondents. Thus the odds ratios for some of the variables were the highest in the unknown categories, indicating a possible uncertainty in the results.

The importance of including job history and exposure measurements in the study of the relationship between women's occupational exposure and health effects has recently been emphasized (34). In the case of asbestos, one should bear in mind that, even though the use of asbestos has decreased in developed nations, it is still widely used in developing countries (35). The focus on asbestos as a health hazard is therefore still a necessity in research. Future research to investigate an association between asbestos and other occupational and environmental exposures and ovarian cancer should be done among large groups of women with considerable exposure.

\section{Acknowledgments}

We wish to thank Jan Ivar Martinsen at the Norwegian Cancer Registry for data assistance and help 
with the statistical analyses. Thanks are also extended to Margareth Kaurin, Torgunn Qvenild, and Sigrunn Beckmann for doing an important job with the interviews.

We also thank the Confederation of Norwegian Business and Industry and Federation of Norwegian Process Industries for giving financial support to this study.

\section{References}

1. Persson I. Estrogens in the causation of breast, endometrial and ovarian cancers - evidence and hypotheses from epidemiological findings. J Steroid Biochem Mol Biol 2000; 74:357-64.

2. La Vecchia C. Epidemiology of ovarian cancer: a summary review. Eur J Cancer Prev 2001;10:125-9.

3. Langseth $\mathrm{H}$, Andersen A. Cancer incidence among women in the Norwegian pulp and paper industry. Am J Ind Med 1999;36:108-13.

4. Cancer Registry of Norway. Cancer in Norway 2000. Oslo: Cancer Registry of Norway; 2000.

5. Germani D, Belli S, Bruno C, Grignoli M, Nesti M, Pirastu $\mathrm{R}$ et al. Cohort mortality study of women compensated for asbestosis in Italy. Am J Ind Med 1999;36:129-34.

6. Bulbulyan MA, Ilychova SA, Zahm SH, Astashevsky SV, Zaridze DG. Cancer mortality among women in the Russian printing industry. Am J Ind Med 1999;36: 166-71.

7. Andersen A, Barlow L, Engeland A, Kjærheim K, Lynge E, Pukkala E. Work-related cancer in the Nordic countries. Scand J Work Environ Health 1999;25 suppl 2:1-116.

8. Kristensen P, Andersen A, Irgens LM, Laake P, Bye AS. Incidence and risk factors of cancer among men and women in Norwegian agriculture. Scand J Work Environ Health 1996;22(1):14-26.

9. Ness RB, Cottreau C. Possible role of ovarian epithelial inflammation in ovarian cancer. J Natl Cancer Inst 1999; 91:1459-67.

10. Heller DS, Gordon RE, Westhoff C, Gerber S. Asbestos exposure and ovarian fiber burden. Am J Ind Med 1996; 29:435-9.

11. Keal EE. Asbestosis and abdominal neoplasms. Lancet 1960;3:1211-6.

12. Acheson ED, Gardner MJ, Pippard EC, Grime LP. Mortality of two groups of women who manufactured gas masks from chrysotile and crocidolite asbestos: a 40-year followup. Br J Ind Med 1982;39:344-8.

13. Wignall BK, Fox AJ. Mortality of female gas mask assemblers. Br J Ind Med 1982;39:34-38.

14. Newhouse ML, Berry G, Wagner JC. Mortality of factory workers in east London 1933-80. Br J Ind Med 1985;42:4-11.

15. Paoletti L, Caiazza S, Donelli G, Pocchiari F. Evaluation by electron microscopy techniques of asbestos contamination in industrial, cosmetic, and pharmaceutical talcs. Regul Toxicol Pharmacol 1984;4:222-35.

16. Cramer DW, Liberman RF, Titus-Ernstoff L, Welch WR, Greenberg ER, Baron JA et al. Genital talc exposure and risk of ovarian cancer. Int J Cancer 1999;81:351-6.

17. Chang S, Risch HA. Perineal talc exposure and risk of ovarian carcinoma. Cancer 1997;79:2396-401.
18. Huncharek M, Geschwind JF, Kupelnick B. Perineal application of cosmetic talc and risk of invasive epithelial ovarian cancer: a meta-analysis of 11,933 subjects from sixteen observational studies. Anticancer Res 2003;23:1955-60.

19. Heller DS, Westhoff C, Gordon RE, Katz N. The relationship between perineal cosmetic talc usage and ovarian talc particle burden. Am J Obstet Gynecol 1996;174:1507-10.

20. Langseth H, Andersen A. Cancer incidence among male pulp and paper workers in Norway. Scand J Work Environ Health 2000;26(2):99-105.

21. Sahle W, Sallsten G, Thoren K. Characterization of airborne dust in a soft paper mill. Ann Occup Hyg 1990; 34:55-75.

22. Shen N, Weiderpass E, Anttila A, Goldberg MS, VasamaNeuvonen KM, Boffetta P, et al. Epidemiology of occupational and environmental risk factors related to ovarian cancer. Scand J Work Environ Health 1998;24(3):175-82.

23. Kauppinen T, Teschke K, Astrakianakis G, Boffetta P, Colin D, Keefe A, et al. Assessment of exposure in an international study on cancer risks among pulp, paper, and paper product workers. AIHAJ 2002;63:254-61.

24. StataCorp. Stata Statistical Software: release 7. College Station (TX): Stata Corporation; 2001.

25. Kane MJ, Chahinian AP, Holland JF. Malignant mesothelioma in young adults. Cancer 1990;65:1449-55.

26. Schneider J, Straif K, Woitowitz HJ. Pleural mesothelioma and household asbestos exposure. Rev Environ Health 1996;11:65-70.

27. Magnani C, Dalmasso P, Biggeri A, Ivaldi C, Mirabelli D, Terracini B. Increased risk of malignant mesothelioma of the pleura after residential or domestic exposure to asbestos: a case-control study in Casale Monferrato, Italy. Environ Health Perspect 2001;109:915-9.

28. Meurman LO, Pukkala E, Hakama M. Incidence of cancer among anthophyllite asbestos miners in Finland. Occup Environ Med 1994;51:421-25.

29. Carel R, Boffetta P, Kauppinen T, Teschke K, Andersen A, Jäppinen $\mathrm{P}$, et al. Exposure to asbestos and lung and pleural cancer mortality among pulp and paper industry workers. J Occup Environ Med 2002;44:579-84.

30. Shields T, Gridley G, Moradi T, Adami J, Plato N, Dosemeci M. Occupational exposures and the risk of ovarian cancer in Sweden. Am J Ind Med 2002;42:200-13.

31. Pukkala E. Cancer risk by social class and occupation: a survey of 109,000 cancer cases among Finns of working age. In: Wahrendorf J, editor. Contributions to epidemiology and biostatistics, vol 7. Basel: Krager, 1995. p 236-8.

32. Costantini AS, Pirastu R, Lagorio S, Miligi L, Costa G. Studying cancer among female workers: methods and preliminary results from a record-linkage system in Italy. J Occup Med 1994;36:1180-6.

33. Hansen J, Boffetta P, Andersen A, Cherrie JW, ChangClaude J, Eilber U, et al. Comparison of information on occupation and lifestyle habits obtained from European man-made vitreous fibre production workers and their relatives. Int J Epidemiol 1997;26:1009-16.

34. McDiarmid MA, Gucer PW. The "GRAS" status of women's work. J Occup Environ Med 2001;43: 665-9.

35. Ramanathan AL, Subramanian V. Present status of asbestos mining and related health problems in India - a survey. Ind Health 2001;39:309-15.

Received for publication: 19 June 2003 